\title{
SOHAM: SEARCHING OUR-OWN HEALTH AFTER MEDICINE By Understanding Physician Mortality Data from The United States Deepak Gupta ${ }^{1}$, Sarwan Kumar ${ }^{2}$, Shushovan Chakrabortty ${ }^{3}$
}

${ }^{1}$ Clinical Assistant Professor, Anesthesiology, Wayne State University, Detroit, Michigan, United States; ${ }^{2}$ Assistant Professor, Internal Medicine, Wayne State University, Detroit, Michigan, United States; ${ }^{3}$ Clinical Assistant Professor, Anesthesiology, Wayne State University, Detroit, Michigan, United States

\begin{tabular}{|c|c|c|c|c|c|c|c|c|}
\hline Abstract & Introduction & Methodology & Results & Conclusion & $\underline{\text { References }}$ & Citation & & es / Figures \\
\hline \multicolumn{9}{|c|}{ Corresponding Author } \\
\hline \multicolumn{8}{|c|}{$\begin{array}{l}\text { Dr Deepak Gupta, Clinical Assistant Professor, Anesthesiology, Wayne State University/Detroit Medical } \\
\text { Center, Box No 162, } 3990 \text { John R, Detroit, MI 48201, United States } \\
\text { E Mail ID: } \underline{\text { dgupta@med.wayne.edu }}\end{array}$} & 回语回 \\
\hline
\end{tabular}

\section{Citation}

Gupta D, Kumar S, Chakrabortty S. Soham: Searching Our-Own Health After Medicine by Understanding Physician Mortality Data From The United States. Indian J Comm Health. 2020;32(1):154-160.

Source of Funding: Nil Conflict of Interest: None declared

\section{Article Cycle}

Received: 13/02/2020; Revision: 09/03/2020; Accepted: 21/03/2020; Published: 31/03/2020

This work is licensed under a Creative Commons Attribution 4.0 International License.

\section{Abstract}

While SEARCHING OUR-OWN HEALTH AFTER MEDICINE (SOHAM), we as aging physicians have to first explore and expose our mortality with underlying uniqueness of causes for physician mortality. Herein, publicly available data at Centers for Disease Control and Prevention from National Occupational Mortality Surveillance program of the National Institute for Occupational Safety and Health comes in handy. As compared to all occupational workers in the United States, intentional self-harm, Parkinson's disease, Alzheimer's and other degenerative disease were more likely causes of death while chronic obstructive pulmonary disease, diseases of the respiratory system, ischemic heart disease and diseases of the heart were less likely causes of death among physicians in the United States. Summarily, we as physicians may have somewhat overcome sufferings of our lungs and hearts but surrendered to sufferings of our brains and minds and therefore must envisage devising physical, psychological, socioeconomic and spiritual interventions for constantly bettering our living.

There is a spiritual word in the East called Soham. In simple terms, it is just the sound emanating from our throats during a breathing exercise-based meditation technique to elevate us spiritually as human beings. (1) However, the word in itself can additionally be an acronym to represent our powerful urge as aging physicians SEARCHING OUR-OWN HEALTH AFTER MEDICINE (SOHAM). In this quest, we have to first explore and expose our mortality as physicians with underlying uniqueness of causes for physician mortality. Consequently, we can relish our successes in overcoming our own diseases while continuing our fights to prevent our failures during the pursuits for our own wholesomely healthy living. To meet our information needs as survivalist physicians, the data available at Centers for Disease Control and Prevention (CDC) from National Occupational Mortality Surveillance (NOMS) program of the National Institute for Occupational Safety and Health (NIOSH) comes in handy. (2) Currently, publicly available proportionate mortality ratio (PMR) query system is limited to $18-64$ years young or 65-90 years old male or female White or Black physicians. (3) As the customized PMR data query system expanding the exploration of PMR data among all other race/ethnicity physicians would have been arduous when potentially marred by all other race/ethnicity physicians' lower numbers resulting in suppressible PMR statistics due to their correspondingly higher propensity for fewer than 5 deaths/cause-ofdeath, we as SOHAM physicians limited our tabulations based on NOMS publicly available data for White and Black physicians hoping that our readers may still be able to non-quantitatively gauge the commonalities and peculiarities among the causes of physician mortality before qualitatively extrapolating these tabulations to all other race/ethnicity physicians inside as well as outside the United States through well-planned future research into the causes of physician mortality locally, regionally and globally.

Based on NOMS publicly available data for White and Black physicians, our tabulation (Tables 1-5) is about 
INDIAN JOURNAL OF COMMUNITY HEALTH / VOL 32 / ISSUE NO 01 / JAN - MAR 2020 NOMS documented PMR corresponding to any particular cause of death whereby PMR as pertaining to our tables is the proportion of physician deaths due to any particular cause of death divided by the proportion of all occupational workers' deaths due to that cause and thereafter multiplied by 100. (4) For any and all of the listed occupations or industries, there is data available for a total 242 specific causes of deaths within NOMS publicly available data domain. As compared to Frank et al (2000) whose tabulations were based on occupational workers' mortality data for the years 1984-1995, (5) NOMS publicly available data domain currently has a PMR Query System encompassing occupational workers' mortality data for the years 1985-1998 which we did not explore for our tabulations. (6) Instead, our tabulations are based on our online access into the NOMS publicly available data domain on November 14, 2019 to explore the most recent PMR Query System which encompasses occupational workers' mortality data for the years 1999, 2003-2004, and 2007-2014 among those whose deaths were certified in 26 states out of 50 states in the United States. (3) As the details about methodology used by NOMS to decipher PMRs corresponding to total 242 specific causes of death among workers of listed occupations or industries can be reviewed by the readers accessing NOMS publicly available data domain, $(7,8)$ these publicly accessible details are not discussed hereafter except for the few specific things as pertaining to our tables which are as follows:

- While running our query in PMR Query System, physicians were categorized into eight categories based on their age (18-64 as young and 65-90 as old), sex (male and female) and race (Black and White) as shown in first columns of (Tables 1-5).

- $\quad$ Thereafter, those causes of death whereby less than five physician deaths had been observed were only cumulatively enumerated as shown in third column of (Table 1).

- $\quad$ Subsequently, those causes of death whereby at least five physician deaths had been observed were summed up to generate the total number of observed physician deaths in each of the abovementioned eight categories as shown in second column of (Table 1 ).

- Among these causes of death whereby at least five physician deaths had been observed, those causes of death whereby physicians' PMR were not different (i.e., PMR 95\% confidence interval crosses 100) from all occupational workers' PMR were only cumulatively enumerated as shown in fourth column of (Table 1).

- $\quad$ Finally, those causes of death whereby physicians' PMR were significantly different from all occupational workers' PMR were initially enumerated cumulatively as shown in fifth column
[SOHAM: SEARCHING...] | Gupta D et al of (Table 1) and thereafter sub-categorized for the tabulations as follows:

- Those causes of death whereby greater proportion (i.e., PMR along with its lower 95\% confidence interval value $\geq 100$ ) of physician deaths had been observed as compared to all occupational workers with stronger statistical significance $p<0.01$ (Table 2) or with weaker statistical significance $\mathrm{p}<0.05$ (Table 3 ).

○ Those causes of death whereby lesser proportion (i.e., PMR along with its upper 95\% confidence interval value $\leq 100$ ) of physician deaths had been observed as compared to all occupational workers with stronger statistical significance $p<0.01$ (Table 4) or with weaker statistical significance $p<0.05$ (Table 5 ).

The key observations during our tabulations for the years 1999, 2003-2004, and 2007-2014 were:

- Physician mortality data may be reflecting traditional demographics of physicians in the United States indicating a potentially historical propensity of physicians towards being White and male in the United States. Among the statistically analyzable physician mortality data ( $n=36635$ : sum total of observed physician deaths as shown in second column of Table 1), almost $70 \%$ data was related to old White male physicians' deaths $(n=25414)$ and $14 \%$ data was related to young White male physicians' deaths $(n=5152)$ while only $14 \%$ data was related to female physicians' deaths ( $n=5183$ : young or old and Black or White) and just $4 \%$ data was related to Black physicians' deaths ( $n=1291$ : young or old and male or female). This can be contrasted to the most current general demographics in the United States wherein White population constitutes around $70 \%$ of general population, female population constitutes around $50 \%$ of general population and Black population constitutes around $15 \%$ of general population. (9) Although crude death rates for NonHispanic White males (around 1110/100,000) and females (around 1060/100,000) are higher than crude death rates for all ethnic groups' males (around 900/100,000) and females (around $830 / 100,000)$ in the United States in contrast to crude death rates for Non-Hispanic Black males (around 850/100,000) and females (around $730 / 100,000)$ being lower than crude death rates for all ethnic groups' males (around 900/100,000) and females (around 830/100,000) in the United States, age-adjusted death rates for Non-Hispanic White males (around 890/100,000) and females (around $640 / 100,000)$ are similar to age-adjusted death rates for all ethnic groups' males (around 860/100,000) and females (around 620/100,000) in the United States contrasting age-adjusted death rates for Non- 
Hispanic Black males (around 1080/100,000) and females (around 730/100,000) being higher than age-adjusted death rates for all ethnic groups' males (around 860/100,000) and females (around $620 / 100,000$ ) in the United States. (10) This skew in crude death rates as compared to age-adjusted death rates may be secondary to Non-Hispanic Whites constituting greater proportions of aging populations in the United States. (11)

- As compared to all occupational workers, intentional self-harm was a more likely cause of death $(p<0.01)$ among physicians except for old Black physicians.

- As compared to all occupational workers, Parkinson's disease, Alzheimer's and other degenerative disease were more likely causes of death $(p<0.01)$ among White male physicians.

- As compared to all occupational workers, chronic obstructive pulmonary disease and diseases of the respiratory system were less likely causes of death $(p<0.01)$ among White physicians.

- As compared to all occupational workers, ischemic heart disease and diseases of the heart were less likely causes of death among White physicians.

Irrespective of us being physicians, death is inevitable due to us being humans. However, how we live our lives before our deaths is what SOHAM all about. As we can infer from above-mentioned data, it seems like we as physicians may have somewhat overcome sufferings of our lungs and hearts but surrendered to sufferings of our brains and minds while seeking the metaphorically healthy trinity of life (brain-heart-lungs). (12) Drawing inspirations from the elucidated causes of death among the physicians in the United States, the physicians of the world can explore and extrapolate their lifestyle data locally, regionally and nationally so as to envisage healthy living as SOHAM physicians globally by devising physical, psychological, socioeconomic and spiritual interventions for constantly bettering their living rather than dying due to physical, psychological, socioeconomic and spiritual causes of their deaths.

\section{Acknowledgement}

The authors are indebted to Andrea L Steege, PhD, MPH, Surveillance Branch MS R18, Division of Surveillance, Hazard Evaluations \& Field Studies, The National Institute for Occupational Safety and Health, Cincinnati, Ohio, United States for answering our emailed and phoned queries regarding National Occupational Mortality Surveillance data which is publicly available at Centers for Disease Control and Prevention website portal.

\section{References}

1. Mukherjee P. 6 Amazing Benefits of Soham Meditation For Leading A Healthy Life. https://www.stylecraze.com/articles/amazing-benefits-of-
[SOHAM: SEARCHING...] | Gupta D et al soham-meditation-to-lead-a-healthy-life/ Accessed on February 13, 2020

2. The National Institute for Occupational Safety and Health (NIOSH). National Occupational Mortality Surveillance (NOMS). About NOMS.

https://www.cdc.gov/niosh/topics/noms/about.html Accessed on February 13, 2020

3. NIOSH (2019). National Occupational Mortality Surveillance (NOMS). U.S. Department of Health and Human Services, Public Health Service, Centers for Disease Control and Prevention, National Institute for Occupational Safety and Health, Division of Surveillance, Hazard Evaluation and Field Studies, Surveillance Branch. https://wwwn.cdc.gov/nioshnoms/occupation2.aspx Accessed on November 14, 2019

4. The National Institute for Occupational Safety and Health (NIOSH). National Occupational Mortality Surveillance (NOMS). Frequently Asked Questions: Information about Proportionate Mortality Ratios (PMRs). https://www.cdc.gov/niosh/topics/noms/faqs.html Accessed on February 13, 2020

5. Frank E, Biola H, Burnett CA. Mortality rates and causes among U.S. physicians. Am J Prev Med. 2000 Oct;19(3):1559. $\quad$ https://doi.org/10.1016/S0749-3797(00)00201-4 Accessed on February 13, 2020

6. The National Institute for Occupational Safety and Health (NIOSH). National Occupational Mortality Surveillance (NOMS). PMR Query System. https://www.cdc.gov/niosh/topics/noms/query.html Accessed on February 13, 2020

7. The National Institute for Occupational Safety and Health (NIOSH). National Occupational Mortality Surveillance (NOMS). Where NOMS Data come from and how the Data are analyzed.

https://www.cdc.gov/niosh/topics/noms/method.html Accessed on February 13, 2020

8. Robinson CF, Walker JT, Sweeney MH, Shen R, Calvert GM, Schumacher PK, Ju J, Nowlin S. Overview of the National Occupational Mortality Surveillance (NOMS) system: leukemia and acute myocardial infarction risk by industry and occupation in 30 US states 1985-1999, 2003-2004, and 2007. Am J Ind Med. 2015 Feb;58(2):123-37. https://www.ncbi.nlm.nih.gov/pmc/articles/PMC4573401/ Accessed on February 13, 2020

9. QuickFacts: United States. https://www.census.gov/quickfacts/fact/table/US/PST045 219 Accessed on February 13, 2020

10. Kochanek KD, Murphy SL, Xu JQ, Arias E. Deaths: Final data for 2017. National Vital Statistics Reports; vol 68 no 9. Hyattsville, MD: National Center for Health Statistics. 2019. https://www.cdc.gov/nchs/data/nvsr/nvsr68/nvsr68_09508.pdf Accessed on February 13, 2020

11. United States Cancer Statistics (USCS): Data Visualizations Tool Technical Notes: Statistical Methods: Incidence and Death Rates. https://www.cdc.gov/cancer/uscs/technical_notes/stat_m ethods/rates.htm Accessed on February 13, 2020

12. Gupta D. Trinity of Life: Brain-Heart-Lungs. WebmedCentral CARDIOLOGY 2019;10(4):WMC005560. http://www.webmedcentral.com/article_view/5560 Accessed on February 13, 2020 
Tables

\section{TABLE 1 NUMERICAL DISTRIBUTION OF CAUSES OF DEATH}

\begin{tabular}{|c|c|c|c|c|}
\hline $\begin{array}{l}\text { Physician } \\
\text { Characteristics }\end{array}$ & $\begin{array}{l}\text { Total Observed } \\
\text { Deaths Across Those } \\
\text { Causes of Death } \\
\text { Whereby At Least } \\
\text { Five Physicians Had } \\
\text { Died }\end{array}$ & $\begin{array}{l}\text { Number of Those } \\
\text { Causes of Death } \\
\text { Whereby Less Than } \\
\text { Five Physicians Had } \\
\text { Died }\end{array}$ & $\begin{array}{l}\text { Number of Those Causes of } \\
\text { Death Whereby Physicians' } \\
\text { PMR Insignificantly Differed } \\
\text { From Overall Occupational } \\
\text { Workers' Population }\end{array}$ & $\begin{array}{l}\text { Number of Those Causes of } \\
\text { Death Whereby Physicians' } \\
\text { PMR Significantly Differed } \\
\text { From Overall Occupational } \\
\text { Workers' Population }\end{array}$ \\
\hline Young Black Female & 222 & 223 & 17 & 2 \\
\hline Old Black Female & 183 & 224 & 17 & 1 \\
\hline Young Black Male & 293 & 217 & 22 & 3 \\
\hline Old Black Male & 593 & 203 & 37 & 2 \\
\hline Young White Female & 1704 & 170 & 51 & 21 \\
\hline Old White Female & 3074 & 159 & 61 & 22 \\
\hline Young White Male & 5152 & 132 & 57 & 53 \\
\hline Old White Male & 25414 & 90 & 77 & 75 \\
\hline
\end{tabular}

TABLE 2 CAUSES OF DEATH WHEREBY GREATER PROPORTION OF PHYSICIAN DEATHS HAPPENED COMPARED TO OVERALL OCCUPATIONAL WORKERS' POPULATION (STRONG STATISTICAL SIGNIFICANCE: $P<0.01)$

\begin{tabular}{|c|c|c|}
\hline Physician Characteristics & Cause Of Death & $\begin{array}{l}\text { PMR (Lower 95\% Cl-Upper 95\% } \\
\text { Cl) }\end{array}$ \\
\hline Young Black Female & Intentional Self Harm & $553(180-1291)$ \\
\hline Old Black Female & - & - \\
\hline \multirow[t]{2}{*}{ Young Black Male } & Intentional Self Harm & $394(189-724)$ \\
\hline & Other Respiratory Disease & $409(165-844)$ \\
\hline Old Black Male & MN Pancreas & $266(133-477)$ \\
\hline \multirow[t]{5}{*}{ Young White Female } & Malignant Neoplasms & $117(104-131)$ \\
\hline & External Causes Of Injury And Poisoning (e-codes) & $128(107-152)$ \\
\hline & MN Lymphatic And Hematopoietic Tissue & $200(137-282)$ \\
\hline & Intentional Self Harm & $212(156-281)$ \\
\hline & Non-Hodgkin's Lymphomas & $272(155-442)$ \\
\hline \multirow[t]{8}{*}{ Old White Female } & MN Digestive Organs And Peritoneum & $154(126-186)$ \\
\hline & Parkinson's Disease (Grouped) & $183(120-269)$ \\
\hline & Parkinsons Disease & $183(120-269)$ \\
\hline & MN Pancreas & $204(148-275)$ \\
\hline & External Causes Of Injury And Poisoning (e-codes) & $205(159-260)$ \\
\hline & MN Other Parts Of Uterus & $216(128-342)$ \\
\hline & MN Peritoneum And Pleura & $544(177-1270)$ \\
\hline & Intentional Self Harm & $677(350-1182)$ \\
\hline \multirow[t]{17}{*}{ Young White Male } & External Causes Of Injury And Poisoning (e-codes) & $142(129-155)$ \\
\hline & Transport Fatalities & $150(123-181)$ \\
\hline & MN Lymphatic And Hematopoietic Tissue & $165(131-206)$ \\
\hline & Malignant Melanoma Of Skin & $178(119-255)$ \\
\hline & MN Pancreas & $180(141-226)$ \\
\hline & Diseases Of The Nervous System And Sense Organs & $182(144-227)$ \\
\hline & MN Of Other And Unspecified Sites & $186(154-222)$ \\
\hline & MN Bone, Connective Tissue, Skin, And Breast & $187(139-246)$ \\
\hline & Intentional Self Harm & $205(179-234)$ \\
\hline & $\begin{array}{l}\text { Anterior Horn Cell Disease Including Motor Neurone Disease } \\
\text { (AMLS) }\end{array}$ & $257(166-379)$ \\
\hline & Multiple Sclerosis And Other Demylenating Disease & $273(149-459)$ \\
\hline & Brain And Nervous System, All Neoplasms Except Secondary & $299(238-370)$ \\
\hline & MN Brain & $305(241-382)$ \\
\hline & MN Brain And Nervous System & $308(244-383)$ \\
\hline & Parkinson's Disease (Grouped) & 347 (159-659) \\
\hline & Parkinsons Disease & 347 (159-659) \\
\hline & Alzheimer's And Other Degenerative Disease & $351(201-570)$ \\
\hline
\end{tabular}


MN Connective And Other Soft Tissue

Railway, Water, Air, And Space Transport Fatalities

Water, Air And Space Transport

Old White Male
Mental Disorders

Mental Disorders, Excluding Schizophrenia And Retardation

Other Respiratory Disease

MN Digestive Organs And Peritoneum

MN Of Other And Unspecified Sites

MN Lymphatic And Hematopoietic Tissue

MN Male Genital Organs

MN Prostate

Chronic Disease Of Endocardium

Leukemia And Aleukemia

Alzheimer's And Other Degenerative Disease

MN Biliary Passages, Liver, And Gall Bladder

Multiple Myeloma

External Causes Of Injury And Poisoning (e-codes)

Accidental Falls

Brain And Nervous System, All Neoplasms Except Secondary

Diseases Of The Nervous System And Sense Organs

Falls Into Hole, One Level To Another Or To Same Level

Acute Myeloid Leukemia

MN Pancreas

MN Brain And Nervous System

MN Brain

MN Bone, Connective Tissue, Skin, And Breast

Parkinson's Disease (Grouped)

Parkinsons Disease

Malignant Melanoma Of Skin

Disorders Of The Peripheral Nervous System

MN Connective And Other Soft Tissue

Intentional Self Harm

Multiple Sclerosis And Other Demylenating Disease

Anterior Horn Cell Disease Including Motor Neurone Disease

(AMLS)

MN Thyroid Gland And Other Endocrine Glands

Injury Of Undetermined Intent

Other Injury Undetermined Intent

Falls, Building Or Structure

Drowning

Accidental Drowning And Submersion

Other Transportation Injuries

Railway, Water, Air, And Space Transport Fatalities

Water, Air And Space Transport
373 (221-589)

$717(468-1050)$

897 (580-1324)

$117(107-128)$

$117(107-128)$

117 (104-131)

$118(110-127)$

123 (108-139)

$130(118-144)$

$130(118-143)$

131 (118-144)

133 (111-157)

134 (114-157)

139 (127-152)

141 (117-168)

143 (113-178)

143 (131-157)

146 (126-169)

157 (126-193)

160 (153-168)

162 (130-199)

170 (134-213)

171 (151-194)

175 (139-218)

176 (139-219)

176 (150-206)

183 (165-204)

183 (165-204)

184 (148-227)

187 (118-280)

199 (132-288)

201 (169-238)

218 (122-360)

279 (221-348)

281 (164-450)

328 (150-622)

377 (163-742)

395 (145-860)

406 (237-651)

406 (237-651)

462 (150-1078)

544 (249-1032)

587 (268-1114)

AMLS: Advanced Medical Life Support Or Amyotrophic Lateral Sclerosis; Cl: Confidence Interval; MN: Malignant Neoplasms; PMR: Proportionate Mortality Ratio

Source Data NOMS. (3)

TABLE 3 CAUSES OF DEATH WHEREBY GREATER PROPORTION OF PHYSICIAN DEATHS HAPPENED COMPARED TO OVERALL OCCUPATIONAL WORKERS' POPULATION (WEAK STATISTICAL SIGNIFICANCE:

\section{$P<0.05$}

Physician

Characteristics

Young Black Female

Old Black Female

Young Black Male

Old Black Male

Young White Female

\section{Cause Of Death}

PMR (Lower 95\% Cl-Upper $95 \% \mathrm{Cl})$

MN Colon

MN Of Other And Unspecified Sites

MN Secondary, III-Defined And Unspecified Sites

MN Brain And Nervous System

MN Brain
-

255 (116-484)

156 (111-215)

159 (108-225)

177 (103-283)

181 (105-290) 
MN Rectum, Rectosigmoid Junction And Anus

MN Kidney

Diseases Of Blood And Blood-Forming Organs

Pneumoconioses (Occupational Lung Diseases) (Coal, Asbestos, Silica, Dust,

Cotton, Other)

Other Injuries

Old White Female

Malignant Neoplasms (MN)

MN Female Genital Organs

MN Biliary Passages, Liver, And Gall Bladder

Transport Fatalities

MN Peritoneum \& Other Digestive Organs

Accidental Poisoning

Young White Male

Malignant Neoplasms (MN)

Symptoms, Signs And III-Defined Conditions, NEC

Non-Hodgkin's Lymphomas

Leukemia And Aleukemia

MN Male Genital Organs

MN Prostate

Accidents Caused By Submersion, Suffocation And Foreign Bodies

Injury Of Undetermined Intent

Other Injury Undetermined Intent

Multiple Myeloma

Drowning

Accidental Drowning And Submersion

Other Diseases Of The Nervous System \& Sense Organs

MN Thyroid Gland And Other Endocrine Glands

Old White Male

Cardiomegaly

Cardiomyopathy

Non-Hodgkin's Lymphomas

Diseases Of Blood And Blood-Forming Organs

All Other Disease Of Blood Forming Organs

Unspecified Falls

Other Malignant Neoplasm Of Skin

Other Diseases Of The Musculoskeletal System

Myoneural Disorders

MN Salivary Glands

Assault And Homicide

Bronchiectasis

MN Nasal Cavities, Middle Ear And Accessory Sinuses

MN: Malignant Neoplasms; NEC: Not Elsewhere Classified; PMR: Proportionate Mortality Ratio

Cl: Confidence Interval; MN: Malignant Source Data NOMS. (3)

TABLE 4 CAUSES OF DEATH WHEREBY LESSER PROPORTION OF PHYSICIAN DEATHS HAPPENED COMPARED TO OVERALL OCCUPATIONAL WORKERS' POPULATION (STRONG STATISTICAL SIGNIFICANCE: P<0.01)

\begin{tabular}{|l|l|l|}
\hline $\begin{array}{l}\text { Physician } \\
\text { Characteristics }\end{array}$ & Cause Of Death & $\begin{array}{l}\text { PMR (Lower 95\% Cl-Upper 95\% } \\
\text { CI) }\end{array}$ \\
\hline Young Black Female & - & - \\
\hline Old Black Female & - & - \\
\hline Young Black Male & - & - \\
\hline Old Black Male & - & - \\
\hline Young White Female & Chronic Obstructive Pulmonary Disease & $33(16-60)$ \\
\cline { 2 - 3 } & Diseases Of The Respiratory System & $63(43-89)$ \\
\hline & MN Trachea, Bronchus And Lung & $67(48-90)$ \\
\hline & MN Respiratory System & $67(49-90)$ \\
\hline \multirow{2}{*}{ Old White Female } & Chronic Obstructive Pulmonary Disease & $67(52-85)$ \\
\hline & Diseases Of The Respiratory System & $75(62-90)$ \\
\hline Young White Male & Chronic Obstructive Pulmonary Disease & $21(12-36)$ \\
\hline & Non-A, Non-B Viral Hepatitis & $36(15-74)$ \\
\hline & Alcoholism & $36(15-70)$ \\
\hline & Mental Disorders Related To Alcohol Abuse & $36(16-72)$ \\
\hline & Mental Disorders Related To Substance Abuse & $39(20-71)$ \\
\hline
\end{tabular}

238 (114-438)

276 (119-545)

341 (125-741)

367 (135-798)

115 (103-127)

149 (107-202)

$182(106-292)$

224 (108-412)

374 (137-814)

424 (138-989)

109 (101-118)

146 (100-206)

156 (105-223)

$156(104-226)$

162 (110-231)

168 (113-242)

184 (105-299)

185 (110-293)

188 (111-297)

189 (110-302)

200 (100-358)

200 (100-358)

229 (105-434)

379 (139-825)

120 (101-143)

120 (101-143)

120 (101-142)

123 (100-151)

133 (102-171)

134 (105-169)

157 (108-221)

160 (105-232)

189 (108-307)

208 (100-382)

246 (123-440)

287 (124-566)

327 (120-712)
33 (16-60)

$63(43-89)$

67 (48-90)

21 (12-36)

36 (15-74)

$36(15-70)$

$39(20-71)$ 
Cirrhosis \& Other Chronic Liver Disease

Other Heart Disease (Pericarditis, Endocarditis, Myocarditis, Etc.)

MN Respiratory System

MN Trachea, Bronchus And Lung

Diseases Of Liver

Diseases Of The Digestive System

Diseases Of The Respiratory System

Infectious And Parasitic Diseases

Ischemic Heart Disease

Diseases Of The Heart

Old White Male
Chronic Obstructive Pulmonary Disease

MN Mesothelioma

MN Trachea, Bronchus And Lung

MN Respiratory System

Diseases Of The Respiratory System

Other Heart Disease (Pericarditis, Endocarditis, Myocarditis, Etc.)

Acute, Chronic, Or Unspecified Renal Failure

Chronic \& Unspecified Nephritis \& Renal Failure \& Other Renal

Sclerosis

Diseases Of Urinary System

Diseases Of Kidney

Diabetes Mellitus

Diseases Of The Genitourinary System

Acute Myocardial Infarction (AMI)

Diseases Of The Digestive System

Ischemic Heart Disease

Diseases Of The Heart
$42(29-58)$

47 (24-82)

$47(38-59)$

$49(39-60)$

$52(39-67)$

$53(42-67)$

$53(40-68)$

$66(48-90)$

$85(76-96)$

88 (80-97)

$46(42-52)$

47 (23-84)

$57(52-63)$

58 (53-64)

70 (65-74)

72 (63-82)

77 (66-89)

79 (67-92)

80 (69-92)

80 (69-92)

82 (73-93)

83 (73-94)

84 (77-91)

$85(74-96)$

93 (89-97)

94 (91-97)

Cl: Confidence Interval; MN: Malignant Neoplasms; PMR: Proportionate Mortality Ratio Source Data NOMS. (3)

TABLE 5 CAUSES OF DEATH WHEREBY LESSER PROPORTION OF PHYSICIAN DEATHS HAPPENED COMPARED TO OVERALL OCCUPATIONAL WORKERS' POPULATION (WEAK STATISTICAL SIGNIFICANCE: P<0.05)

\begin{tabular}{|c|c|c|}
\hline Physician Characteristics & Cause Of Death & PMR (Lower 95\% Cl-Upper 95\% CI) \\
\hline Young Black Female & Diseases Of The Heart & $58(35-91)$ \\
\hline Old Black Female & Ischemic Heart Disease & $52(24-98)$ \\
\hline Young Black Male & - & - \\
\hline Old Black Male & Chronic Obstructive Pulmonary Disease & $38(12-89)$ \\
\hline \multirow[t]{3}{*}{ Young White Female } & Infectious And Parasitic Diseases & $48(23-89)$ \\
\hline & Ischemic Heart Disease & $69(50-94)$ \\
\hline & Diseases Of The Heart & $76(60-95)$ \\
\hline \multirow[t]{6}{*}{ Old White Female } & Other Heart Disease (Pericarditis, Endocarditis, Myocarditis, Etc.) & $65(44-93)$ \\
\hline & Diseases Of The Digestive System & $68(46-97)$ \\
\hline & MN Trachea, Bronchus And Lung & $78(61-99)$ \\
\hline & MN Respiratory System & $79(62-100)$ \\
\hline & Ischemic Heart Disease & $83(71-97)$ \\
\hline & Diseases Of The Heart & $88(78-98)$ \\
\hline \multirow[t]{4}{*}{ Young White Male } & Mental Disorders & $58(35-90)$ \\
\hline & Mental Disorders, Excluding Schizophrenia And Retardation & $59(35-92)$ \\
\hline & MN Biliary Passages, Liver, And Gall Bladder & $66(42-98)$ \\
\hline & Diabetes Mellitus & $72(53-95)$ \\
\hline \multirow[t]{6}{*}{ Old White Male } & MN Larynx & $49(24-91)$ \\
\hline & Disorders Of Gallbladder And Biliary Tract & $52(26-94)$ \\
\hline & Hypertension Without Heart Disease & $77(59-98)$ \\
\hline & Symptoms, Signs And III-Defined Conditions, NEC & $80(64-99)$ \\
\hline & MN Colon & $84(72-99)$ \\
\hline & Other Diseases Of Digestive System & $85(72-100)$ \\
\hline
\end{tabular}

